\title{
GO+ DALAM MENUNJANG INT+ UNTUK PENGELOLAAN DATA CMB PADA PERGURUAN TINGGI
}

\author{
Muhamad Yusup ${ }^{1}$ \\ Untung Rahardja ${ }^{2}$ \\ Susan Oktaviani ${ }^{3}$ \\ e-mail: yusup@raharja.info; untung@raharja.info; \\ susan.oktaviani@raharja.info
}

Diterima : 10 Juni 2014 / Disetujui : 16 Juli 2014

\begin{abstract}
The development of information technology, especially in the era of globalization software much influence on human life and the world of education. And supported by increased public participation in information technology to education in particular. Higher Education is a leading university that has had the best level of recognition from the National Accreditation Board makes a lot of enthusiasts who signed up. College Marketing Division has Integram system that supports data management Prospective New Students and can only be accessed on campus. Therefore we need a system that can be used online. To support this necessary or membership management student called INT +. There are four problems in the system that is running INTEGRAM system. There are three objectives in this study. Researchers using the prototype as a research method. Data collection techniques used were observation to stakeholders in the marketing division. This study is limited to the process of getting the data presentation area in the form of name, email and telephone number Prospective New Student. GO + is the latest version of GO that are connected to the Internet can be accessed anywhere. In the implementation shown prototype GO+ with INT+ , so it can be concluded that GO + with INT+ to maximize the performance of Personil Marketing .
\end{abstract}

Keywords: GO+,INT+, Personil Marketing, Perguruan Tinggi.

1. Dosen Jurusan Sistem Informasi, STMIK Raharja

Jl. Jend Sudirman No. 40 Modern Cikokol-Tangerang Telp. 5529692

2. Dosen Jurusan Sistem Informasi, STMIK Raharja

Jl. Jend Sudirman No. 40 Modern Cikokol-Tangerang Telp. 5529692

3. Mahasiswa Jurusan Sistem Informasi, STMIK Raharja

Jl. Jend Sudirman No. 40 Modern Cikokol-Tangerang Telp. 5529692 


\section{ABSTRAKSI}

Perkembangan teknologi informasi, khususnya perangkat lunak dalam era globalisasi banyak memberikan pengaruh terhadap kehidupan manusia dan dunia pendidikan. Dan didukung oleh peran serta masyarakat yang meningkat dalam memperoleh pendidikan khususnya teknologi informasi. Perguruan Tinggi Raharja merupakan Perguruan Tinggi unggulan yang telah memiliki pengakuan level terbaik dari Badan Akreditasi Nasional (BAN) menjadikan banyak peminat yang mendaftar. Divisi marketing Perguruan Tinggi Raharja mempunyai sistem Integram yang menunjang pengelolaan data Calon Mahasiswa Baru (CMB) dan hanya dapat diakses di lingkungan kampus. Oleh karena itu diperlukan sistem yang dapat digunakan secara online Untuk menunjang hal tersebut diperlukan pengelolaan mahasiswa atau membership yang disebut INT+. Terdapat empat permasalahan didalam sistem sistem INTEGRAM yang sedang berjalan. Terdapat 3 tujuan dalam penelitian ini. Peneliti menggunakan metode prototype sebagai metode penelitiannya. Teknik pengumpulan data yang digunakan adalah observasi kepada stakeholder pada bagian marketing. Penelitian ini dibatasi ada proses mendapatkan data Presentasi Luas yang berupa nama,email dan nomor telepon Calon Mahasiswa Baru. GO+ merupakan versi terbaru dari GO yang sudah terkoneksi jaringan internet sehingga dapat di akses dimanapun. Pada implementasinya ditampilkan prototype GO+ dengan INT+, sehingga dapat disimpulkan bahwa GO+ dengan INT+ dapat memaksimalkan kinerja Personil Marketing.

Kata kunci: GO+,INT+, Personil Marketing, Perguruan Tinggi.

\section{PENDAHULUAN}

Kemajuan teknologi informasi saat ini telah banyak membantu pekerjaan manusia dalam segala aspek. Setiap kegiatan organisasi saat ini telah didukung oleh kemajuan teknologi informasi, termasuk juga dalam bidang pendidikan. Peran teknologi informasi saat ini juga telah didukung dengan jaringan internet, yaitu kemudahan dari segi akses serta penyimpanan data secara cloud. Internet (kependekan dari interconnection-networking) adalah seluruh jaringankomputer yang saling terhubung menggunakan standarsistem global Transmission Control Protocol/Internet Protocol Suite (TCP/IP) sebagai protokol pertukaran paket (packet switching communication protocol) untuk melayani miliaran pengguna di seluruh dunia. Rangkaian internet yang terbesar dinamakan Internet. Cara menghubungkan rangkaian dengan kaidah ini dinamakan internetworking (“antarjaringan”). 


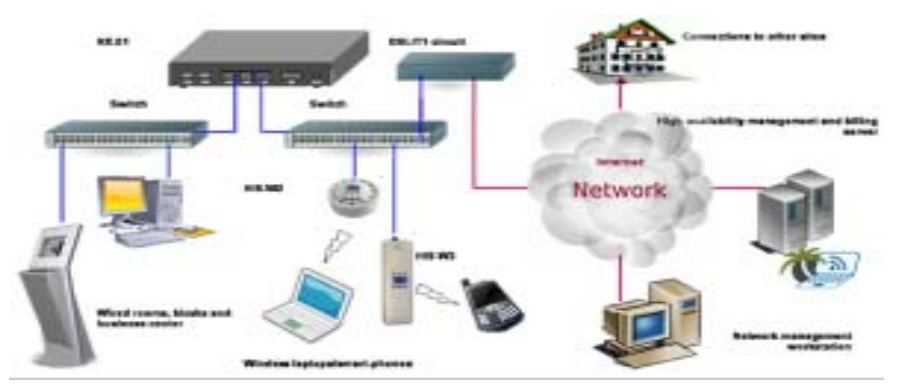

Gambar 1 Internet Network

Internet (inter-network) dapat diartikan jaringan computer luas yang menghubungkan pemakai komputer satu komputer dengan computer lainnya dan dapat berhubungan dengan computer dari suatu negara ke negara di seluruh dunia ,dimana didalamnya terdapat berbagai aneka ragam informasi fasilitas layanan internet browsing atau surfing yaitu kegiatan "berselancar" di internet.

Lembaga pendidikan formal maupun non-formal sangat membutuhkan sistem kerja yang efektif, efisien, dan data yang terpusat. Teknologi informasi telah banyak membantu pekerjaan manusia seperti di bidang marketing contohnya dalam pengelolaan data marketing. Pengelolaan data saat ini sudah banyak yang memanfaatkan teknologi informasi, sehingga mempermudah tugas - tugas marketing. Data yang terpusat serta kemudahan akses menjadi poin terpenting di dalam suatu organisasi khususnya marketing. Menjaga hubungan baik antara marketing dengan customer merupakan hal terpenting dalam menjalankan suatu bisnis .

Di era globalisasi saat ini menjaga hubungan dengan calon customer dengan cara mengirimkan informasi - informasi yang terkait merupakan poin terpenting dalam promosi marketing yang harus dijalankan oleh suatu organisasi yang disebut email campaign.

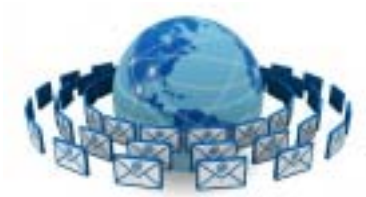

Gambar 2 Email Campaign 
Email campaign adalah email marketing yang sering digunakan dalam kegiatan organisasi khususnya dibidang marketing untuk mengirim email promote kepada customer secara terpusat pada satu tempat dan dapat mengirim ke banyak contact email, dengan tujuan untuk menjaga hubungan baik antara marketing dengan customer . Dengan membuat template email campaign yang menarik serta dapat dikirim ke banyak contact email secara langsung, hal ini sangat memudahkan pekerjaan seorang marketing dalam suatu organisasi.

Melalui peranan teknologi sistem informasi untuk membantu proses pengelolaan data dan email campaign pada suatu organisasi kepada calon customer, diharapkan dapat meningkatkan kinerja organisasi tersebut khususnya di bagian marketing.

Kemudian untuk menunjang penggunaan email campaign juga diperlukan contact sebagai subject atau detail penerima pesan (customer). Contact merupakan data terpenting dari customer yang harus kita dapatkan dan kita kelola dengan baik. Untuk mengelola ratusan contact customer, diperlukan sistem yang dapat membuat contact dalam jumlah banyak dan dapat disimpan serta dikelola secara terus menerus, sehingga data akan tersimpan dengan baik. Contact person dari customer dapat berisi nama, telepon, alamat, email, dan lain-lain.

Divisi Marketing Perguruan Tinggi Raharja telah menggunakan sistem INTEGRAM (Integrated Raharja Marketing) untuk menunjang kegiatan pendataan Calon Mahasiswa Baru. Sedangkan INT+ adalah singkatan dari Integrated Raharja Marketing Plus merupakan versi terbaru dari INTEGRAM yang dapat diakses dengan jaringan internet dan juga didukung oleh GOint+(GO+ dan INT+) Platform.

GO adalah singkatan dari Green Orchestra merupakan salah satu product REC (Raharja Enrichment Centre) di Perguruan Tinggi Raharja yang masih menggunakan jaringan LAN dengan fitur - fitur yang digunakan untuk keperluan rincian biaya perkuliahan dan lain -lain.

Sedangkan GO+ merupakan versi terbaru dari GO yang sudah terkoneksi jaringan internet sehingga dapat di akses dimanapun. Di dalam Penelitian ini terdapat tiga tujuan penelitian yaitu yang pertama penelitian ini bertujuan untuk meningkatkan kegiatan promosi kampus kepada Calon Mahasiswa Baru. Tujuan kedua adalah untuk menunjang pengelolaan data Calon Mahasiswa Baru. Tujuan ketiga adalah untuk meningkatkan kinerja Personil Marketing. 


\section{PERMASALAHAN}

Perkembangan teknologi informasi di era globalisasi in sudah berkembang sangat pesat. Kemajuan dibidang teknologi informasi telah banyak membantu kehidupan manusia.

Pada saat ini seluruh perguruan tinggi juga memiliki sistem pengelolaan data calon mahasiswa baru. Perguruan Tinggi Raharja bermula dari sebuah lembaga kursus komputer yang bernama LPPK (Lembaga Pendidikan dan Pelatihan Komputer) Raharja yang kemudian menjadi sebuah instistusi pendidikan tinggi di kota Tangerang. Dengan meningkatnya minat masyarakat terhadap Perguruan Tinggi Raharja juga semakin menunjang banyaknya jumlah calon mahasiswa yang ikut bergabung menjadi Pribadi Raharja. Seiring dengan peningkatan jumlah pada pendaftaran mahasiswa juga diperlukan pengelolaan data mahasiswa yang dapat diakses dimanapun.

Di Perguruan Tinggi Raharja pengelolaan calon mahasiswa baru hingga menjadi mahasiswa dilakukan oleh team bagian marketing dengan menggunakan sistem INTEGRAM (Integrated Raharja Marketing). Marketing sangat berperan dalam mempromosikan Perguruan Tinggi Raharja kepada calon mahasiswa baru. Banyak program - program yang dilaksanakan oleh marketing, seperti GCC Tour,dan lain lain. Ruang lingkup penelitian ini yaitu difokuskan pada proses Presentasi Luas,yaitu cara untuk mendapatkan data Calon Mahasiswa Baru. Didalam pengelolaan data calon mahasiswa baru yang terdiri dari nama, alamat, email, dan asal sekolah masih menggunakan sistem yang berjalan pada Integram Marketing, pengelolaan data mahasiswa saat ini sudah terkomputerisasi namun masih menggunakan LAN (Local Area Network).

Intisari dari permasalahan digambarkan dalam bentuk Mind Mapping, seperti gambar berikutini:

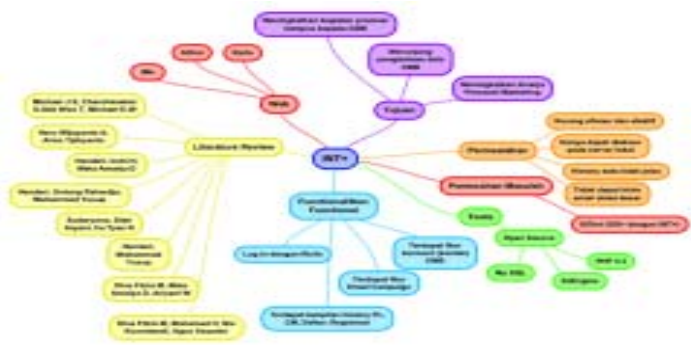

Gambar 3. Mind Mapping Penerapan GOint+ 
Mind Map ini terdiri dari beberapa konten, diantaranya yaitu : Tujuan, Permasalahan, Pemecahan Masalah, Tools, Fucntional/ Non Functional, Web, dan Literature Review.

Konten-konten yang dibuat tersebut memiliki cabang lain seperti pada konten Tujuan yang terdiri dari 4 cabang, Permasalahan dibagi menjadi 4 cabang, Pemecahan Permasalahan 1 cabang, Tools terdapat 1 cabang yang dibagi lagi menjadi 3 percabangan, Functional/Non Functional terdiri dari 5 cabang, lalu Literature Review terdapat 8 percabangan. Berdasarkan Mind Mapping di atas, maka perumusan masalah dalam penelitian ini yaitu Permasalahan pertama adalah bagaimana korelasi pengolahan data calon mahasiswa baru menggunakan sistem Integram yang sedang berjalan saat ini? Apakah sudah optimal? Pengelolaan data calon mahasiswa baru pada bagian marketing belum optimal dikarenakan data Calon Mahasiswa Baru yang didapat tidak dikelola dengan baik. Data yang berupa nama, email, alamat dan nomor telepon merupakan data penting bagi Personil Marketing, yaitu dapat dimanfaatkan dalam kegiatan promosi sehingga selanjutnya dapat meningkatkan kemungkinan Calon Mahasiswa Baru untuk bergabung dengan Perguruan Tinggi Raharja. meskipun belum tentu mendaftar. Kegiatan marketing yang sering mendatangi sekolah - sekolah diharapkan dapat mendata nama siswa, telepon serta email. Sedangkan sistem INTEGRAM belum dapat dijalankan atau diakses diluar lingkungan kampus. Permasalahan yang kedua adalah apakah progress dari pencapaian Presentasi Luas, Counseling Murni, Daftar dan Registrasi tidak dapat diketahui dengan jelas proses statusnya pada sistem INTEGRAM? Dalam hal ini tampilan progress peningkatan dari suatu pencapaian merupakan hal yang sangat penting. Dengan tampilan progress pencapaian yang mudah dimengerti oleh Personil Marketing (user friendly), diharapkan dapat meningkatkan kinerja Personil Marketing.

Permasalahan yang ketiga yaitu bagaimana caranya agar marketing dapat memberikan informasi - informasi terbaru tentang Kampus secara cepat,dan menarik? Pada saat ini pemberian informasi hanya melalui telepon, mengirim surat, memberikan brosur. Pemberian informasi tersebut kurang efektif dan memakan biaya pengeluaran bagi marketing.

Permasalahan yang keempat yaitu INTEGRAM hanya dapat diakses pada server lokal kampus, sehingga tidak memungkinkan bagi personil marketing untuk dapat mengaksesnya di luar kampus. Pada saat ini kebutuhan akan sistem berbasis cloud sudah cukup banyak digunakan oleh organisasi-organisasi. Begitu pula dengan kebutuhan Personil Marketing saat ini, untuk mempermudah pekerjaan input data 
dimana saja dan kapan saja, diperlukan sistem dengan akses ke jaringan internet. Sehingga diharapkan dapat meningkatkan kinerja Personil Marketing.

Berikut ini adalah tampilan dari data warehouse sistem INTEGRAM yang sedang berjalan. Terlihat tabel informasi dibawah ini masih kurang dapat dipahami.

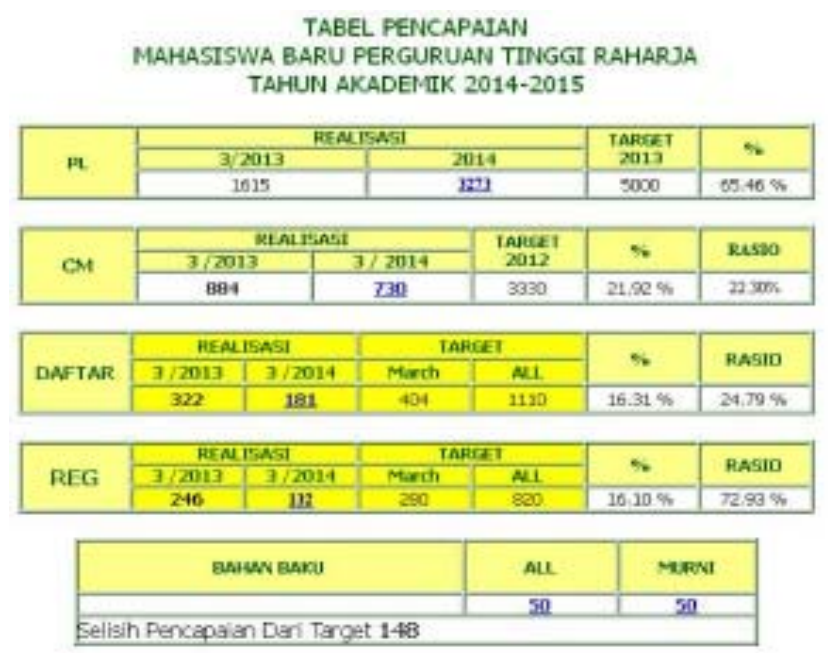

Gambar 4. Tabel Pencapaian Mahasiswa Baru Pada Sistem INTEGRAM

\section{LITERATURE REVIEW}

Banyak penelitian yang sebelumnya dilakukan mengenai pengelolaan data mahasiswa berbasis cloud atau sudah online. Dalam upaya pengembangan sistem online pengelolaan data mahasiswa ini perlu dilakukan studi pustaka sebagai salah satu penerapan metode penelitian yang akan dilakukan. Diantaranya adalah mengidentifikasikan kesenjangan (identify gaps), menghindari pembuatan ulang (reinventing the wheel), mengidentifikasikan metode yang pernah dilakukan, meneruskan penelitian sebelumnya, serta mengetahui orang lain yang spesialisasi dan area penelitiannya sama dibidang ini. Beberapa Literature review tersebut adalah sebagai berikut :

1. Penelitian yang dilakukan oleh Dina Fitria Murad, Muhamad Hariyanto, Nia Kusniawati, Agus Asyanto dari Perguruan Tinggi Raharja pada Tahun 2013 
yang berjudul “Aplikasi Intelligence Website Untuk Penunjang Laporan PAUD Pada HIMPAUDI Kota Tangerang”. Dalam penelitian ini menjelaskan bahwa penggunaan komputer dalam kehidupan sehari-hari telah menjadi hal yang biasa dan dapat diterapkan secara fleksibel dimana saja dan kapan saja. Sebagian besar masyarakat telah familiar dalam menggunakan komputer. Keandalan perangkat keras dan perangkat lunak serta didukung oleh sumber daya manusia (brainware) yang memadai akan menjadikan masalah ketersediaan informasi terkendali dengan sebuah sistem informasi. Sistem informasi yang mudah digunakan dan efektif digunakan secara hirarki akan menunjang kegiatan laporan dan dapat digunakan sebagai sistem penunjang keputusan bagi lembaga-lembaga yang menaungi lembaga pendidikan tersebut.[1]

2. Penelitian ini dilakukan oleh Henderi, Indri Handayani, Meta Amalya Dewi dari Perguruan Tinggi Raharja pada Tahun 2012 yang berjudul "Business Intelligence Development Model Using Star Schema Methodology”. Dalam penelitian ini dijelaskan bahwa sistem business intelligence yang biasanya digunakan di organisasi profit telah digunakan juga di berbagai lembaga pemerintahan. Tujuan utamanya adalah untuk meningkatkan layanan kepada publik, efisiensi biaya, dan efektifitas kerja yang diembankan kepada organisasi yang dimaksud. Dalam mengimplementasikan business intelligence di suatu lembaga pemerintah, hal utama yang diperhatikan adalah bahwa business intelligence harus mendukung pencapaian visi, misi, dan strategi organisasi dalam mencapai tingkat kinerja organisasi yang diinginkannya. Oleh karena itu sistem business intelligence sebagai tools pengukur kinerja enterprise yang dihasilkan telah diuji coba dan diimplementasikan pada bagian penerimaan mahasiswa baru di Perguruan Tinggi Raharja.[2]

3. Penelitian ini dilakukan oleh Henderi dan Muhammad Yusup dari Perguruan Tinggi Raharja Tahun 2007 yang berjudul “Design Dan Implementasi Data Warehouse Sebagai Pengukur Kinerja”. Dalam penelitian ini menjelaskan bahwa keunggulan bagi manajemen sistem data warehouse dapat menyediakan dan menyampaikan data dan informasi kepada manajemen dan user secara real time dan up to date serta peningkatan pengelolaan sistem informasi yang ada pada organisasi.[3]

4. Penelitian ini dilakukan oleh Heru Wijayanto Aripradono dan Aries Tjahyanto, dari STIE IEU Surabaya yang berjudul “Analisa Dan Design Sistem Informasi Pemasaran Di STIE IEU Surabaya”. Dalam penelitian ini menjelaskan bahwa 
STIE IEU sebagai salah satu perguruan tinggi di Surabaya dengan fokus pada international bisnis sejak tahun 1990, menyadari betapa pentingnya pengembangan sistem informasi pemasaran(SIPI) untuk meningkatkan kinerja pemasaran. Terutama di dalam mengikuti tingkat kompetisi perguruan tinggi yang semakin ketat dan kompleks. Sistem informasi pemasaran yang dikembangkan tersebut merupakan rekayasa ulang proses bisnis yang berjalan saat ini di IEU dan diharapkan mampu peningkatan efisiensi kinerja dari proses pemasarannya.[4]

5. Penelitian ini dilakukan oleh Sudaryono, Diah Aryani, Ira Tyas Ningrum Tahun 2011 dari Perguruan Tinggi Raharja yang berjudul "Cloud Computing: Teori Dan Implementasinya Dalam Dunia Bisnis Dan Pemasaran”. Dalam penelitian ini dijelaskan bahwa Keuntungan dari penggunaan cloud computing ini sangat banyak. Mulai dari kemudahan akses dimana aplikasi dan data dapat diakses kapanpun dan dimanapun. Demikian juga untuk urusan penghematan. Pengguna tidak perlu memikirkan untuk membeli sebuah komputer terbaru dengan memori yang besar beserta berbagai software pendukung. Di masa yang akan datang semua disediakan pada cloud computing. Bila cloud computing ini dikerjakan atau diakses pada sebuah perangkat portabel seperti smartphone atau tablet yang dapat mengakses Internet via WiFi,bayangkan kemudahan yang dapat diperoleh.[5]

Dari lima literature review yang ada, telah banyak penelitian mengenai pengelolaan data penerimaan mahasiswa baru, bussiness intelligence, data mining, data warehouse serta pembahasannya. Namun dapat disimpulkan pula bahwa belum ada peneliti yang secara khusus membahas menegenai Perancangan Sistem Informasi INT+ dengan GO+ Platforms Dalam Mendukung Pengelolaan Data CMB Pada Perguruan Tinggi Raharja.

\section{PEMECAHAN MASALAH}

Dengan melihat permasalahan yang terjadi maka perlu adanya sistem berbasis web yang dapat diakses menggunakan jaringan internet sehingga mampu menyajikan informasi sehingga dapat menunjang kebutuhan personil marketing. Berdasarkan permasalahan yang telah dijabarkan penulis berusaha menjawab semua permasalahan dengab merancang sebuah aplikasi sistem GO+ dalam menunjang INT+ dalam pengelolaan data CMB pada Perguruan Tinggi. Solusi dari permasalahan yang pertama 
adalah dengan menggunakan sistem $\mathrm{GO}+$ yang dapat diakses kapanpun dan di manapun dengan menggunakan jaringan internet diharapkan dapat meningkatkan kinerja personil marketing. Kemudian solusi dari permasalahan yang kedua adalah pada sistem GO+ dapat menampilkan progress pencapaian PL, CM, Daftar dan Registrasi. Untuk permasalahan yang ketiga solusinya adalah pemberian informasi maupun promosi terkait program studi dalam Perguruan Tinggi Raharja dapat dilakukan dengan cara email Campaign atau email marketing, yaitu pengiriman email promosi dengan skala besar dan menarik. Dan permasalahan yang terakhir untuk log in dapat diakses dengan jaringan internet dan menggunakan email Raharja.info.

Disini penulis akan sedikit menerangkan beberapa definisi yang terkait dengan sistem GO+ yaitu sebagai berikut:

1. Open source adalah perangkat lunak yang dapat digunakan secara bebas oleh siapa saja. Perangkat lunak ini tidak dikoordinasi oleh suatu individu/ lembaga pusat, tetapi oleh para pelaku yang bekerja sama dengan memanfaatkan kode sumber (source-code) yang tersebar dan tersedia bebas (biasanya menggunakan fasilitas komunikasi internet). Jadi bisa disimpulkan bahwa open source merupakan software yang kode programnya disediakan oleh pengembangnya untuk umum agar dapat dipelajari cara kerjanya, diubah atau dikembangkan lebih lanjut, dan disebarluaskan. Istilah open source (kode program terbuka) sendiri baru dipopulerkan tahun 1998.[6]

2. Customer Management Relationship adalah sebuah strategi bisnis menyeluruh dalam suatu perusahaan yang memungkinkan perusahaan tersebut secara efektif bisa mengelola hubungan dengan para pelanggan. Dapat juga diartikan sebagai usaha sebuah perusahaan untuk berkonsentrasi menjaga pelanggan dengan mengumpulkan segala bentuk interaksi pelanggan baik itu lewat telepon, email, masukan di situs atau hasil pembicaraan dengan staf sales dan marketing. Sehingga secara garis besar dapat disimpulkan bahwa CRM adalah sebuah istilah industri TI untuk metodologi, strategi, perangkat lunak (software) dan atau aplikasi berbasis web yang mampu membantu sebuah perusahaan untuk mengelola hubungannya dengan para pelanggan.[7]

3. Pemasaran dalam suatu perusahaan memegang peranan yang sangat penting, karena pemasaran merupakan salah satu kegiatan yang dilakukan untuk mempertahankan kelangsungan hidup perusahaan, melakukan perkembangan terhadap perusahaan untuk pencapaian tujuan perusahaan dalam memperoleh 
laba. Masyarakat awam pada umumnya seringkali menyamakan pemasaran dengan penjualan. Pandangan ini terlalu sempit karena penjualan hanya satu dari beberapa aspek yang ada pada pemasaran. Pemasaran berusaha mengidentifikasi kebutuhan dan keinginan konsumen pasar sasarannya serta bagaimana memuaskan mereka melalui proses pertukaran dengan tetap memperhatikan semua pihak dan tujuan terkait dengan kepentingan perusahaan. [8]

4. Calon Mahasiswa Baru adalah calon pribadi raharja yang belum melakukan proses daftar atau registrasi. Presentasi Luas adalah penghimpunan data calon mahasiswa seminim - minimnya nama dan nomor telepon melalui seminar JDK, pameran, stand, sponsorship, dan lain - lain. Counseling Murni adalah penghimpun data calon mahasiswa melalui presentasi tatap muka dengan waktu presentasi minimal 15 menit dengan tujuan memberikan informasi seputar penerimaan mahasiswa baru. Daftar adalah kelanjutan dari aktifitas counseling murni ditandai dengan terjualnya formulir pendaftaran. Registrasi adalah kelanjutan dari aktifitas daftar ditandai berubahnya status calon mahasiswa menjadi mahasiswa Perguruan Tinggi Raharja dengan membayar biaya perlengkapan kuliah dan dinyatakan berhak mendapatkan nomor induk mahasiswa. [9]

5. Dalam merancang sebuah aplikasi atau sistem, diperlukan metode - metode atau langkah-langkah dalam pembangunan atau pengembangan sistem. Dalam penelitian ini, penulis melakukan perancangan sistem dengan metode prototype. Prototyping sebagai suatu paradigma baru dalam pengembangan sistem informasi akuntansi, tidak hanya sekedar suatu evolusi dari metode pengembangan sistem informasi yang sudah ada tetapi sekaligus merupakan revolusi dalam pengembangan sistem informasi akuntansi. Metode Prototyping merupakan model kerja dari sebuah sistem informasi akuntansi yang belum lengkap. [10]

Teknik yang dilakukan dalam penerapan metode prototyping adalah sebagai berikut

1. Teknik perancangan model, merupakan bagian terpenting dalam metode prototyping yang digunakan sebagai alat untuk menjadikan model menjadi sistem informasi yang sebenarnya. 
2. Teknik perancangan dialog, disusun agar keterlibatan user menjadi jelas dan fleksibel. Aspek perancangan dalam dialog mencakup keseluruhan unsur seperti perintah-perintah dalam sistem informasi. 3. Teknik simulasi, digunakan untuk menunjukkan bagaimana cara kerja sebuah sistem informasi yang akan diterapkan dengan baik untuk mengoperasikan sistem informasi yang akan digunakan.

Dalam men-visualisasikan rancangan sistem, penulis menggunakan Unified Modelling Language (UML) sebagai tools yang digunakan dalam merancang sistem, dan menggunakan software Visual Paradigm, menggunakan Macromedia Dreamweaver CS5 untuk mendesign sistemnya, PHP dan MySQL sebagai rancangan aplikasinya, serta X2Engine untuk mendukung aplikasi cloud GOint+.

Di bawah ini merupakan gambaran Flowchart alur program yang berjalan dari sistem GOint (GO+ dengan INT+) dalam menunjang INT+ untuk pengelolaan data CMB pada Perguruan Tinggi.

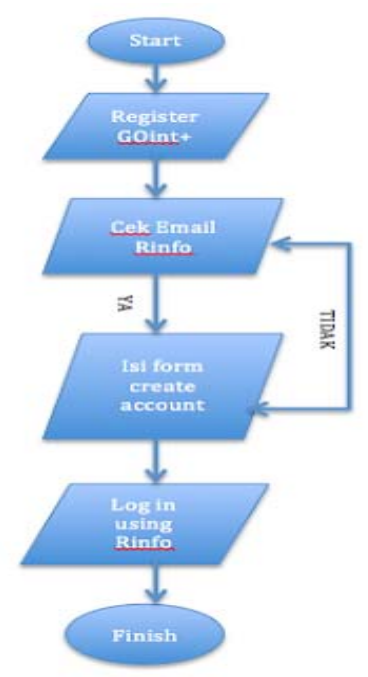

Gambar 5. Flowchart alur Register GOint+ Crew

Pada proses Presentasi Luas pada sistem GOint+ dimulai dari register GOint+ yaitu mengisi form Register yang terdapat di http://goiz.ilearning.me, kemudian membuka email Rinfo dna klik email invitation dari Admin untuk kemudian mengisi 
form create account. Setelah itu user dapat mencoba untuk melakukan log in ke dalam sistem GOint+ menggunakan email Rinfo.

Dibawah ini merupakan Usecase Diagram Presentasi Luas pada Sistem GOint. Di dalam usecase tersebut hanya menjelaskan sistem Presentasi Luas yang dilakukan oleh seorang Personil Marketing kepada Calon Mahasiswa Baru menggunakan GOint+, dengan tujuan untuk mendapatkan data contact sebanyak - banyaknya.

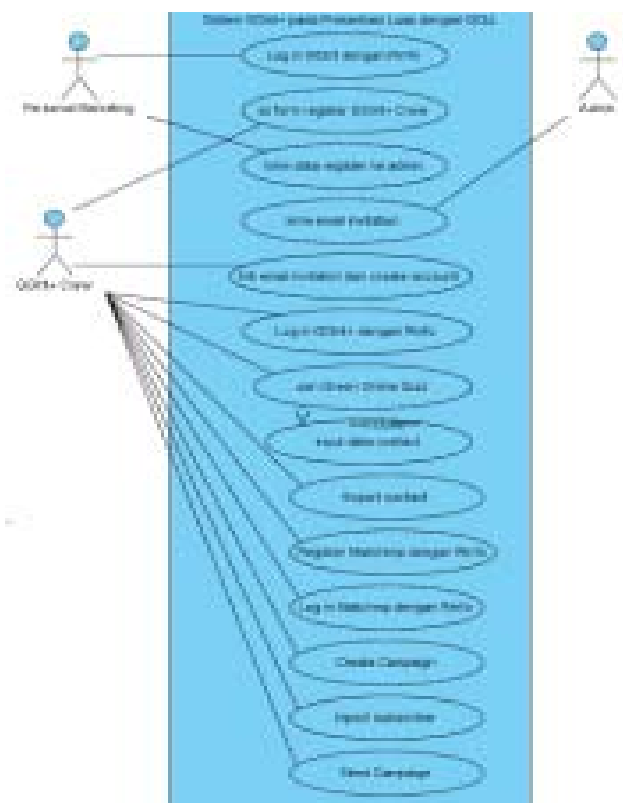

Gambar 6. Usecase Diagram Presentasi Luas GOint+

Pemikiran ide yang akan dituangkan berdasarkan sumber-sumber informasi yang telah didapat. Sehingga rancangan aplikasi dimulai dengan mendapatkan open source, dimulai dengan mendownload open source serta aplikasi pendukung dalam pengaplikasian tersebut, yaitu dengan mengedit dan mengatur sesuai kebutuhan pada aplikasi Dreamweaver. Sistem GOInt+ juga menggunakan Php dan MySQL untuk mendukung rancangan aplikasinya. Sistem GOint+ juga didukung oleh open source X2Engine CRM yang dapat di download serta dapat dihubungkan dengan database GOint + sehingga terhubung ke jaringan internet. Dan didukung juga dengan email Raharja.info sebagai akses log in GOint + dan http://ilearning.me serta dalam kegiatan Presentasi Luas GOint+ juga didukung oleh MailChimp untuk melakukan promosi 
denga tujuan mendapatkan data contact sebanyak - banyaknya. MailChimp adalah penyedia layanan email pemasaran dan merupakan suatu aplikasi berbasis web.

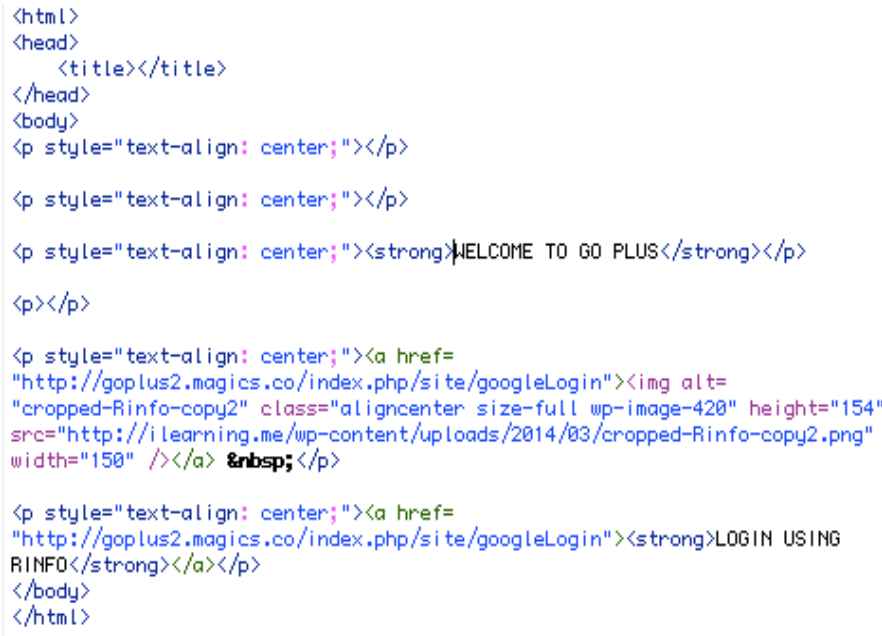

Gambar 7. Listing program Log in pada GOint+ system

\section{IMPLEMENTASI}

Sistem INTEGRAM yang berjalan saat ini masih menggunakan server kampus, sehingga hanya dapat diakses di lingkungan kampus saja. Dalam hal ini belum dapat menunjang kebutuhan personil marketing. Karena banyak kegiatan personil marketing diluar kampus, yaitu mengunjungi siswa - siswi di SMU/SMA/Sederajat. Pada tahap input data calon mahasiswa pada saat kegiatan GCC Tour dikampus atau kegiatan mengunjungi sekolah - sekolah saat ini masih menggunakan kertas, sehingga tidak efisien dan efektif. Pada tahap pemberian informasi terkait kampus kepada Calon Mahasiswa Baru masih menggunakan telepon. Hal ini kurang efektif dan efisien. Solusi dari permasalahan pada poin kesatu, kedua dan ketiga di atas adalah dengan menggunakan sistem GO+ untuk menunjang kegiatan - kegiatan Personil Marketing yang berhubungan dengan Calon Mahasiswa Baru, yang disebut dengan INT+. Sistem GO+ yang diaplikasikan dengan INT+ dalam menunjang pengelolaan data Calon Mahasiswa Baru adalah sistem informasi berbasis website, karena dapat diakses dengan mudah,dimana saja dan kapan saja. Serta dapat menanggulangi permasalahan-permasalahan yang telah disebutkan diatas. Personil Marketing dapat 
otomatis log in ke GOint+ $(\mathrm{GO}+$ dan INT+) saat telah log in / masuk ke email Rinfo. Personil Marketing dapat langsung create contact (untuk CMB) dan dapat di assign to (ditugaskan) ke staff yang bertanggungjawab untuk menanganinya, juga dapat edit informasi contact tersebut. Serta personil marketing juga dapat mengirimkan email campaign ke contact tersebut secara massal melalui Campaign pada Mailchimp.

Terdapat juga fitur Accounts, yaitu untuk menampung data mahasiswa atau orang yang memberikan informasi kepada calon mahasiswa baru terkait promosi kampus yang disebut dengan Student Get Student. Manfaat dari penelitian ini adalah untuk mendapatkan data Presentasi Luas sebanyak - banyaknya, data tersebut berupa nama, email dan nomor telepon Calon Mahasiswa Baru. Tujuan dari penelitian ini adalah untuk meningkatkan kegiatan promosi kampus kepada Calon Mahasiswa Baru, menunjang kegiatan pengelolaan data Calon Mahasiswa Baru, dan juga dapat meningkatkan kegiatan Personil Marketing. Fitur - fitur yang terdapat pada aplikasi ini memang difokuskan untuk sistem record data - data Calon Mahasiswa Baru serta kegiatan-kegiatan promosi yang lebih efisien dan efektif. Hal ini juga bermanfaat untuk meningkatkan kinerja Personil Marketing, yang sangat menyingkat waktu dan lebih cepat dan efisien, dikarenakan dapat diakses di jaringan internet.

Sebagai penerapan GO+ dalam menunjang INT+ dalam pengelolaan data Calon Mahasiswa Baru , maka dibuatlah sebuah sistem informasi berbasis web pada Marketing, yang dapat ditampilkan pada tampilan seperti dibawah ini:

\section{a. Prototype Log in GOint otomatis dengan Rinfo}

Personil Marketing dapat otomatis Log in jika sudah memiliki akun email Raharja.info. Sehingga pada saat sudah log in email Rinfo, maka dengan membuka link url http://goplus2.magics.co secara otomatis akan langsung muncul ke halaman utama GOint+ atau INT+. Hal ini sangat memudahkan bagi user atau pengguna, tanpa harus mengisiusername maupun password terlebih dahulu, maka dapat langsung $\log$ in secara otomatis.

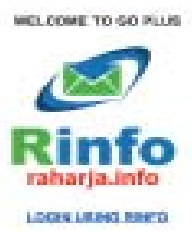

Gambar 8. Tampilan Log in dengan Rinfo 
b. Prototype Proses Status GOint+ Proses Status Presentasi Luas, Counseling Murni, Daftar dan Registrasi tersimpan dengan baik dan juga dapat dilihat pada setiap proses, details, dan tanggal.

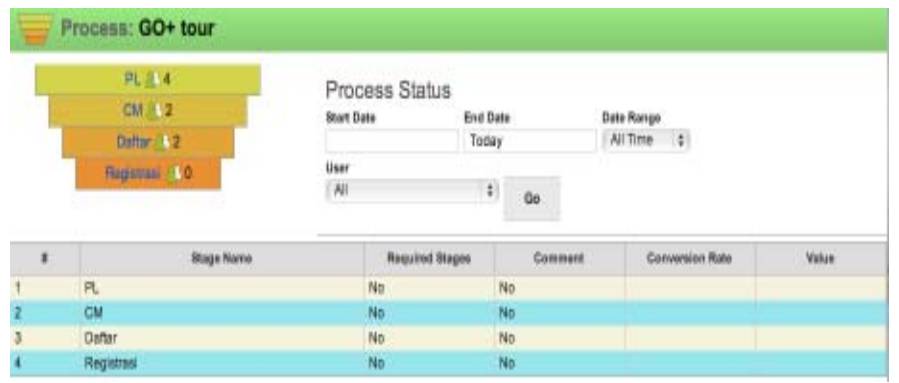

Gambar 9. Tampilan Proses Status pada GOint+ $(G O+$ dan INT+)

c. Prototype Accounts GOint+

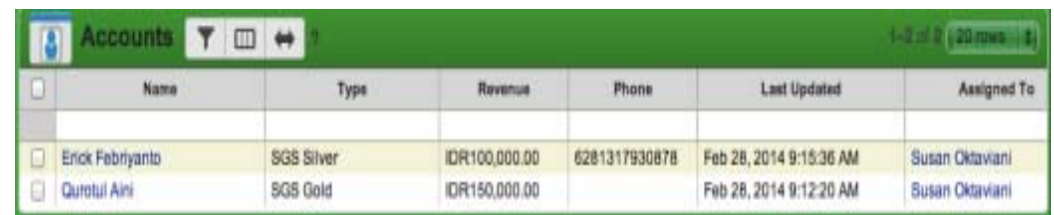

Gambar 10. Tampilan Accounts pada GOint+ $(G O+$ dan INT+)

Accounts atau kontak merupakan data - data dari calon mahasiswa baru maupun mahasiswa yang merekomendasikan Calon Mahasiswa Baru kepada marketing. Disini data - data kontak terpelihara dengan baik. terdapat data nama, telepon, type recomendasi, history yang jelas (terakhir kali data di update) dan kepada Personil Marketing yang ditugaskan.

d. Tampilan Campaign pada Mailchimp

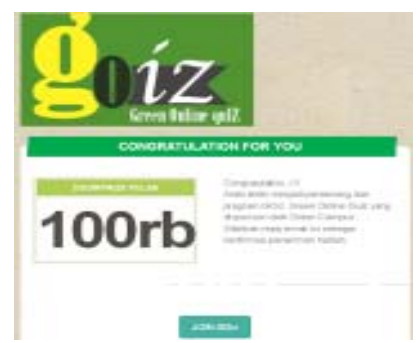

Gambar 11. Tampilan Campaign GOiz 
Campaign GOiz berisi program quiz yang terdapat link join us menuju form input account yang secara otomatis masuk ke dalam sistem GOint+. Dengan Campaign dari MailChimp, dapat menambah banyak contact yang berisi data nama, email dan nomor telepon tanpa harus mengeluarkan biaya besar seperti GCC Tour, yaitu hanya memerlukan biaya promosi sebesar seratus ribu rupiah sebagai hadiah pemenang kuis.

\section{KESIMPULAN}

Kesimpulan berdasarkan rumusan masalah pada penelitian ini adalah:

Sistem INTEGRAM yang berjalan saat ini masih menggunakan server kampus, sehingga hanya dapat diakses di lingkungan kampus saja. Dalam hal ini belum dapat menunjang kebutuhan personil marketing. Karena banyak kegiatan personil marketing diluar kampus,yaitu mengunjungi siswa - siswi di SMU/SMA/Sederajat. Pada tahap input data Calon Mahasiswa Baru pada saat kegiatan GCC Tour dikampus atau kegiatan mengunjungi sekolah-sekolah saat ini masih menggunakan kertas, sehingga tidak efisien dan efektif. Solusi dari permasalahan tersebut adalah dengan menggunakan sistem GO+ untuk menunjang kegiatan-kegiatan Personil Marketing yang berhubungan dengan Calon Mahasiswa Baru, yang disebut dengan INT+. Sistem GO+ yang diaplikasikan dengan INT+ dalam menunjang pengelolaan data Calon Mahasiswa Baru adalah sistem informasi berbasis website, karena dapat diakses dengan mudah,dimana saja dan kapan saja. Kemudahannya yaitu single sign on with Rinfo, yaitu log in otomatis jika sudah membuka email Rinfo (tidak menggunakan username dan password). Sehingga dapat disimpulkan bahwa dengan adanya GO+ dalam menunjang INT+ untuk pengelolan data CMB pada Perguruan Tinggi diharapkan dapat menunjang kegiatan - kegiatan Personil Marketing.

\section{DAFTAR PUSTAKA}

[1] Adit Tia. “Tinjauan Atas Pengembangan Sistem Informasi Akutansi Persediaan Barang Dagang Pada Misyelle Group Bandung”. 2010. Bandung: UNIKOM. Diakses pada tanggal 30 Mei 2014 dari http://elib.unikom.ac.id/files/disk1/ 435/jbptunikompp-gdl-adittianim-21719-13-unikom_a-l.pdf 
[2] Definisi CRM. 2012. Sumatera Utara: Universitas Sumatera Utara. Diakses pada tanggal 13 Mei 2014 dari http://repository.usu.ac.id/bitstream/ 123456789/27701/4/Chapter\%20II.pdf

[3] Definisi INTEGRAM. 2007. Perguruan Tinggi Raharja. Diakses pada tanggal 20 Mei 2014. Dari http://192.168.25.3/rec5/komando/PPI/ Integram_Versi1.htm

[4] Dina Fitria Murad, Muhamad Hariyanto, Nia Kusniawati dan Agus Asyanto. 2013. “Aplikasi Intelligence Website Untuk Penunjang Laporan PAUD Pada HIMPAUDI Kota Tangerang”. CCIT Journal ISSN : 1978-8282 Vol. 7 No. 1. Tangerang : Perguruan Tinggi Raharja.

[5] Henderi, Indri Handayani, dan MetaAmalya Dewi. 2012. "Business Intelligence Development Model Using Star Schema Methodology”. CCIT Journal ISSN : 1978-8282 Vol. 5 No. 3. Tangerang : Perguruan Tinggi Raharja.

[6] Henderi, Muhammad Yusup. 2007. "Design Dan Implementasi Data Warehouse Sebagai Pengukur Kinerja”. CCIT Journal ISSN: 19788282. Vol.1. No.1. Tangerang: Perguruan Tinggi Raharja.

[7] Heru Wijayanto Aripradono dan Aries Tjahyanto, . “Analisa Dan Design Sistem Informasi Pemasaran Di STIE IEU Surabaya”. Diakses pada tanggal 24 Maret 2014 darihttp://directory.umm.ac.id/SIP/Jurnal-Heru01\%282008\%29.pdf

[8] Sudaryono, Diah Aryani, dan Ira Tyas Ningrum. 2011. "Cloud Computing: Teori Dan Implementasinya Dalam Dunia Bisnis Dan Pemasaran”. CCIT Journal ISSN : 1978-8282 Vol.5 No. 2. Tangerang : Perguruan Tinggi Raharja.

[9] STMIK Raharja. Diakses pada 14 April 2014 dari http://rww.stmikraharja.com/syela/web/definisi.htm

[10] Universitas Widyatama. Diakses pada tanggal 24 Maret 2014 dari http:// repository.widyatama.ac.id/bitstream/handle/10364/599/bab2.pdf?sequen 
